\title{
Effect of pre-slaughter conditions on physico-chemical characteristics of mutton from three sheep breeds slaughtered at a smallholder rural abattoir
}

\author{
A.Y. Chulayo \& V. Muchenje \\ Department of Livestock and Pasture Science, Meat Science, University of Fort Hare \\ P/Bag 1314, Alice, 5700, South Africa
}

(Received 13 October 2012; Accepted 20 November 2012; First published online 15 July 2013)

Copyright resides with the authors in terms of the Creative Commons Attribution 2.5 South African Licence.
See: http://creativecommons.org/licenses/by/2.5/za
Condition of use: The user may copy, distribute, transmit and adapt the work, but must recognise the authors and the South African Journal of Animal
Science.

\begin{abstract}
The effects of pre-slaughter conditions and breed on physico-chemical characteristics of mutton were determined. The study was conducted at Adelaide Municipal abattoir in the Eastern Cape Province, South Africa. Records were taken from 84 sheep from the South African Mutton Merino, Blackhead Persian and Dorper breeds as identified on arrival at the abattoir. The South African Mutton Merino (SAMM) had the highest values for meat $\mathrm{pH}$ at 24 hours $\left(\mathrm{pH}_{24}\right)(5.9 \pm 0.64)$, lightness; $\mathrm{L}^{*}(34.2 \pm 0.97)$, yellowness; $\mathrm{b} *(12.2$ $\pm 0.50)$ and Warner-Braztler shear force WBSF $(26.8 \pm 1.51)$. Linear relationships were also observed between pre-slaughter variables and physico-chemical characteristics of mutton. Principal Component Analysis (PCA) showed a large variation being contributed by meat $\mathrm{pH}_{24}$ and $\mathrm{L}^{*}$. It was therefore concluded that, transport time and lairage duration negatively affected the quality of mutton. Furthermore, breed affected the physico-chemical characteristics of meat.
\end{abstract}

Keywords: Colour, meat $\mathrm{pH}_{24}$, Principal Component Analysis, transport time, Warner Braztler Shear Force ${ }^{\#}$ Corresponding author: vmuchenje@ufh.ac.za

\section{Introduction}

Meat quality is a measure of tenderness, flavour, juiciness and cooking loss. Tenderness and juiciness are some of the determinants of overall meat eating quality while meat $\mathrm{pH}\left(\mathrm{pH}_{24}\right)$ and colour affect the keeping quality and visual appeal of meat. Meat $\mathrm{pH}$ is related to other meat quality attributes such as colour (Muchenje et al., 2008; 2009; Schönfeldt \& Strydom, 2011). However, meat quality is affected by animalrelated factors and pre-slaughter conditions.

Animal-related factors affecting meat quality include age, breed and the sex of the animal (MartinezCerezo et al., 2005; Du Plessis \& Du Rand, 2012). Cloete et al. (2008) reported that breed had an effect on carcass composition of meat while Ljungberg et al. (2007) and Rodríguez et al. (2011) reported that the preslaughter environment, loading, transportation; unloading and the period of stay at the lairages affect the quality of meat.

Studies (Miranda-de la Lama et al., 2009; Rodríguez et al., 2011) conducted around this topic have been executed in controlled experimental environments where conditions were controlled. Meanwhile animals under practical conditions do not get enough recovery time due to management practices at the abattoir (Assylyng et al., 2001; Engstrom et al., 2010; Chulayo, 2011). In South Africa, information regarding the effects of pre-slaughter variables such as transport time, stocking density, ambient temperature and lairage duration and animal-related factors on physico-chemical characteristics of meat under practical conditions is limited. Therefore, the objective of the current study was to determine the effects of preslaughter conditions on physico-chemical characteristics of lamb and mutton from three sheep breeds kept in South Africa. 


\section{Materials and Methods}

The study was carried out at Adelaide Nxuba Municipal abattoir located $200 \mathrm{~km}$ west of East London, $32^{\circ} .8^{\circ} \mathrm{S}$ and $26^{\circ} .9^{\circ} \mathrm{E}$ in the Amatole District of the Eastern Cape Province, South Africa. Eighty-four sheep of different breeds; South African Mutton Merino (SAMM), Dorper (DP) and Blackhead Persian (BP) sheep that were presented for slaughter at a low-throughput abattoir were used. There were 28 animals per breed used in the study. They three different farms and each farmer supplied all the above-mentioned breeds. The animals were brought to the abattoir in different loads using the same light duty vehicle. The size of the vehicle was $3.6 \mathrm{~m}$ x $4.4 \mathrm{~m}$. Fifteen to 20 sheep were transported per load. The stocking density was calculated by dividing the floor area by the number of animals in the vehicle and the density was expressed as animals $/ \mathrm{m}^{2}$.

Times of departure from the farm and arrival at the abattoir were used to calculate the journey duration. The animals used were castrates with overall slaughter weight of approximately $39.5-40 \mathrm{~kg}$. The animals were brought to the abattoir for slaughter once they attained 39.5 or $40 \mathrm{~kg}$. The sheep were grouped according to age. The grouping was as follows: Group 1 (6 - 8 months), Group 2 (9 - 12 months) and Group 3 (13 - 16 months). The animals were rested for 1.30 minutes to $2 \mathrm{~h}$ in lairage before slaughter. The animals were electrically stunned at $650 \mathrm{~V}$ for 5 seconds and were allowed to bleed for six minutes. After slaughter, carcasses were stored in a cold room at $2{ }^{\circ} \mathrm{C}$ for 24 hours.

For the determination of meat $\mathrm{pH}$ at $\mathrm{pH}_{24}$, colour ( $\mathrm{L}^{*}$ - lightness, $\mathrm{a}^{*}$ - redness and $\mathrm{b}^{*}$ - yellowness), thawing (TL \%), cooking loss (CL \%) percentages and Warner Braztler Shear Force (WBSF), samples of the Muscularis longissimus thoracic et. lumborum (LTL) were removed from each of the 84 carcasses. The muscle was removed by cutting a sample of approximately $14 \times 9 \times 3 \mathrm{~cm}$ at the loin region while the carcasses were still hanging. The average weight of the meat samples was $191 \mathrm{~g}$.

A portable fibre-optic pH meter probe (CRISON pH 25 Instruments, Spain) was used to measure the $\mathrm{pH}$ of the carcasses 24 hours post mortem from the LTL muscle. The $\mathrm{pH}$ meter was calibrated before taking measurements using $\mathrm{pH} 4$, $\mathrm{pH} 7$ and $\mathrm{pH} 9$ standards solutions (CRISON Instruments, Spain). The carcases were classified as normal ( $\mathrm{pH}<5.7$ ) or as dry firm dark (DFD) mutton ( $\mathrm{pH}>5.7$ ) (Rodríguez et al., 2011). The L*; a, and b* values were determined at the butchery 24 hours after slaughter using a Minolta colourguide 45/0 BYK-Gardener GmbH machine with a 20 mm diameter measurements area and illuminant D65day light, $10^{\circ}$ standard observer. The machine was calibrated each day before taking measurements using the green, black and white standard colour samples provided for this purpose. The readings were taken by rotating the Colour Guide $90^{\circ}$ between measurements so as to obtain the average value for the colour. Each sample was vacuum-packed, kept in a cooler box with ice packs and further stored in the refrigerator at 0 - 4 ${ }^{\circ} \mathrm{C}$ until they were analysed two weeks later for the WBSF determination.

In preparation for thawing and cooking loss determination, frozen samples were thawed overnight and weighed. They were placed in a plastic bag and cooked using a water bath at $85{ }^{\circ} \mathrm{C}$ for 45 minutes (Ding et al., 2010). After cooking, the samples were cooled down to room temperature and weighed again to obtain the cooking loss. Thawing and cooking losses were then calculated using the following formulas:

$$
\begin{aligned}
& \text { Thawing (thaw)loss } \%=\left[\frac{\text { (weight from freezer }- \text { weight after thawing) }}{\text { weight from freezer }}\right] * 100 \\
& \text { Cooking Loss (CL) } \%=\left[\frac{\text { weight before cooking }- \text { weight after cooking }}{\text { weight before cooking }}\right] * 100
\end{aligned}
$$

Tenderness of meat was then determined using an Instron 3344 Universal Testing (cross head speed at $400 \mathrm{~mm} / \mathrm{min}$, one shear in the centre of each core). Following cooking, sub-samples of specified core diameter were cored parallel to the grain of the meat. The samples were sheared perpendicular to the fibre direction using a Warner Braztler Shear Force (WBSF) device mounted on the Instron. The mean maximum load recorded for the three cores represented the average of the peak force in Newton's $(\mathrm{N})$ for each sample.

The data for the effects of breed on $\mathrm{pH}_{24}, \mathrm{~L}^{*}, \mathrm{a}^{*}, \mathrm{~b}^{*}$, thawing loss (TL \%), cooking loss (CL \%) and WBSF of meat were analysed using the PROG GLM of SAS (2003). Significant differences between least square group means of $\mathrm{pH}_{24}, \mathrm{~L}, \mathrm{a}^{*}, \mathrm{~b}^{*}$, Thaw $\%$, CL\% and WBSF values were compared using the Least Significance Difference (LSD) procedure (SAS, 2003). Prediction equations between transport time, lairage 
duration and lairage duration in relation to physico-chemical characteristics of mutton were determined using regression analysis (PROG REG, SAS, 2003). The following model was used:

where

$$
\mathrm{y}=\mathrm{a}+\mathrm{b}_{1} \mathrm{X}_{1}+\mathrm{b}_{2} \mathrm{X}_{2}+\mathrm{b}_{3} \mathrm{X}_{3}+\mathrm{e},
$$

$\mathrm{y}=$ Response variable $\left(\mathrm{pH}_{24}, \mathrm{~L}, \mathrm{a}^{*}, \mathrm{~b} * \mathrm{TL} \%, \mathrm{CL} \%\right.$ and WBSF);

$\mathrm{a}=$ intercept, $\mathrm{b}=$ co-efficient variable, $\mathrm{X}_{1}=$ transport time, $\mathrm{X}_{2}=$ lairage duration, $\mathrm{X}_{3}=$ stocking density and $\mathrm{e}=$ the error term.

\section{Results and Discussion}

There were significant breed effects on $\mathrm{pH}_{24}, \mathrm{~L}^{*}, \mathrm{~b}^{*}, \mathrm{CL} \%$ and WBSF of the mutton (Table 1). Among the three breeds, SAMM had the highest $\mathrm{pH}_{24}(5.9 \pm 0.06), \mathrm{L}^{*}(34.2 \pm 0.97), \mathrm{b} *(12.2 \pm 0.50)$ and WBSF (26.8 \pm 1.51$)$ values. The results are in agreement with Cloete et al. (2008) who also reported that differences in $\mathrm{pH}_{24}$ were breed-dependent. Meat $\mathrm{pH}$ is also related to other meat quality variables such as colour, tenderness, flavour and aroma (Muchenje et al., 2008; 2009). The lighter meat observed for SAMM as compared to DP and BP shows that some breeds are more susceptible to stress (Mota-Rojas et al., 2006) leading to myoglobin breakdown as a result of lactic acid prior to slaughter.

Lactic acid production reduces glycogen reserves which are credited to other activities that occur at post mortem and require energy for breaking down the bonds between muscles to improve tenderness (Martinez-Cerezo et al., 2005). In this study tenderness in BP improved with decreasing $\mathrm{pH}_{24}$. These results contradict with the findings of Miranda-de la Lama et al. (2009) who reported that tenderness increased with $\mathrm{pH}_{\mathrm{u}}$. However, Muchenje et al. (2008) indicated that higher ultimate $\mathrm{pH}\left(\mathrm{pH}_{\mathrm{u}}\right)$ may not always be involved in the toughness of meat as compared to other meat parameters.

Table 1 Mean $( \pm \mathrm{SE})$ for $\mathrm{pH} 24, \mathrm{~L}^{*}, \mathrm{a}^{*}, \mathrm{~b}^{*}$, cooking loss and WBSF of mutton as affected by breeds

\begin{tabular}{lcccc}
\hline \multirow{2}{*}{$\begin{array}{l}\text { Meat quality } \\
\text { characteristics }\end{array}$} & \multicolumn{3}{c}{ Breed } & $\begin{array}{c}\text { Significance } \\
\text { level }\end{array}$ \\
\cline { 2 - 5 } & Blackhead Persian & Dorper & SAMM & \\
\hline No. & 28 & 28 & 28 & $* * *$ \\
$\mathrm{pH}_{24}$ & $5.6^{\mathrm{a}} \pm 0.06$ & $5.8^{\mathrm{b}} \pm 0.05$ & $5.9^{\mathrm{b}} \pm 0.06$ & $* * *$ \\
$\mathrm{~L}^{*}$ & $28.8^{\mathrm{a}} \pm 0.86$ & $31.7^{\mathrm{b}} \pm 0.82$ & $34.2^{\mathrm{c}} \pm 0.97$ & NS \\
$\mathrm{a}^{*}$ & $16.7 \pm 0.49$ & $17.2 \pm 0.47$ & $17.6 \pm 0.56$ & $* *$ \\
$\mathrm{~b}^{*}$ & $9.1^{\mathrm{a}} \pm 0.44$ & $11.2^{\mathrm{b}} \pm 0.42$ & $12.2^{\mathrm{b}} \pm 0.50$ & $* * *$ \\
CL\% & $35.5^{\mathrm{b}} \pm 2.17$ & $33.0^{\mathrm{a}} \pm 2.08$ & $29.3^{\mathrm{a}} \pm 2.46$ & $* *$ \\
WBSF & $22.9^{\mathrm{a}} \pm 1.33$ & $26.4^{\mathrm{b}} \pm 1.28$ & $26.8^{\mathrm{b}} \pm 1.51$ & \\
\end{tabular}

\footnotetext{
${ }^{\mathrm{a}, \mathrm{b}, \mathrm{c}}$ Means with the different superscript in the same row differ significantly. Level of significance $=* * P<0.01$, *** $P<0.001$, NS: not significant, $\mathrm{pH}_{24}$ : - meat $\mathrm{pH}$; L*: lightness; $\mathrm{a}^{*}$ : redness; $\mathrm{b}^{*}$ : yellowness;

CL\% - cooking loss percentage.

WBSF: Warner Braztler Shear Force; SAMM: South African Mutton Merino.
}

Table 2 represents the relationship between pre-slaughter variables (lairage duration and transport time) and physico-chemical characteristics ( $\mathrm{pH}_{24}$, colour, thawing loss, cooking loss and WBSF) of mutton. A positive relationship between $\mathrm{pH}_{24}$ with transportation time $(r=+0.008)$ and lairage duration $(r=+0.001)$ was observed. Stressful environment reduces glycogen levels in the muscles resulting in lower lactic acid production. Lightness had a negative $(P<0.001)$ relationship with distance duration, stocking density and lairage duration. Increase in transport time $(r=-0.06)$ and lairage duration $(r=-0.02)$ resulted in darker meat. There was a negative relationship observed between $b^{*}$ and lairage duration, stocking density.

Animals lose energy during transportation and this energy may be gained at the lairages prior to animal slaughter (Jacob et al., 2005a). In the current study, stocking density, transport time and lairage 
duration had a negative impact on mutton quality. This agrees with findings by Jacob et al. (2005b) that longer lairage period (days) results in darker mutton.

Table 2 Linear relationships between physico-chemical characteristics of mutton and pre-slaughter conditions

\begin{tabular}{lll}
\hline Parameter $(\mathrm{Y})$ & \multicolumn{1}{c}{ Equation } & Significance \\
\hline $\mathrm{pH}_{24}$ & $3.46(0.41)+0.008(0.001) \mathrm{X}_{1}^{* * *}+0.001(0.0003) \mathrm{X}_{2} * * *+0.02(0.006) \mathrm{X}_{3} * *$ & $* * *$ \\
$\mathrm{~L}^{*}$ & $52.2(7.16)-0.06(0.02) \mathrm{X}_{1}{ }^{*}-0.02(0.006) \mathrm{X}_{2} * * *-0.34(0.10) \mathrm{X}_{3} * *$ & $* * *$ \\
$\mathrm{a}^{*}$ & $13.2(5.5)+0.01(0.01) \mathrm{X}_{1}^{* *}$ & $* *$ \\
$\mathrm{~b}^{*}$ & $18.2(3.3)-0.03(0.01)-0.01(0.003) \mathrm{X}_{2} * * *-0.11(0.05) \mathrm{X}_{3} * * *$ & $* * *$
\end{tabular}

Significance difference $=* P<0.05, * * \mathrm{P}<0.01, * * * P<0.001$.

$\mathrm{X}_{1}$ : transport time; $\mathrm{X}_{2}$ : lairage duration; $\mathrm{X}_{3}$ : stocking density; $\mathrm{pH}_{24}$ : meat $\mathrm{pH}$; $\mathrm{L}^{*}$ : lightness; $\mathrm{a}^{*}$ : redness;

b*: yellowness.

\section{Conclusion}

Pre-slaughter conditions, such as transport time and lairage duration negatively affected physicochemical characteristics of mutton under practical conditions. There were also breed differences in meat quality. Under practical conditions, animals experience stressful conditions that reduce the quality of their meat. Therefore, during this period, animals must be monitored and handled humanely for improved meat quality.

\section{Acknowledgements}

The authors acknowledge National Research Fund (NRF Project T079) and Red Meat Research and Development Trust of South Africa (RMRDT-SA) for assisting in funding this research. This study was conducted at the Adelaide Nxuba municipal abattoir.

\section{References}

Aaslyng, M.A. \& Gade, P.B., 2001. Low stress pre-slaughter handling: effect of lairage time on the meat quality of pork. Meat Sci. 57, 87-92.

Cloete, J.J.E., Hoffman, L.C. \& Cloete, S.W.P., 2008. Carcass characteristics and meat quality of progeny of five Merino dam lines crossed with Dormer and Suffolk sires. S. Afr. J. Anim. Sci. 38, 355-366.

Chulayo, A.Y., 2011. Effects of pre-slaughter sheep handling and animal-handling factors on creatine kinase levels and physico-chemical attributes of mutton. MSc. thesis, University of Fort Hare, South Africa.

Ding, W., Kou, L., Cao, B. \& Wei, Y., 2010. Meat quality parameters of descendants by grading hybridization of Boer goat and Guazhong Dairy goat. Meat Sci. 84, 323-328.

Du Plessis, H.J. \& Du Rand, G.E., 2012. The significance of traceability in consumer decision making towards Karoo lamb. Food Res. Intl. 47 (2), 210-217.

Engstrom, M., Sanchez ,W., Stone, W. \& St-Pierre, N.R., 2010.Applications of population data analysis in on-farm dairy trials. J. Anim. Sci. 88, 25-31.

Jacob, R.H., Pethick, P.W. \& Chapman, H.M., 2005a. Muscle glycogen concentrations in commercial consignments of Australian lamb measured on farm and post-slaughter after three different lairage periods. Aust. J. Exp. Agric. 45, 543-552.

Jacob, R.H., Walker, P.J., Skerritt, J.W., Davidson, R.H., Hopkins, D.L., Thompson, J.M. \& Pethick, D.W., 2005b. The effect of lairage time on consumer sensory scores of the M. longissimus thoracic et lumborum from lambs and lactating sheep. Aust. J. Exp. Agric. 45, 535-542.

Ljungberg, D., Gebresentbet, G. \& Aradom, S., 2007. Logistics chain of animal transport and abattoir operations. Biosystems Eng. 96, 267-277. 
Martinezo-Cerezo, S., Sańudo, C., Panea, B., Medel, I., Delfa, R., Sierra, I., Beltran, J.A., Cepero, R. \& Olleta, J.L., 2005. Breed, slaughter and ageing time effects on physio-chemical characteristics of lamb meat. Meat Sci. 69, 325-333.

Miranda-de la Lama, G.C., Villarroel, M., Olleta, J.L., Alierta, S., Sańudo, C. \& Maria, G.A., 2009. Effect of the pre-slaughter logistic chain on meat quality of lambs. Meat Sci. 83, 606-609.

Mota-Rojas, D., Becerril, M., Lemus, C., Sanchez, P., Gonzalez, M., Olmos, S.A., Ramirez, A. \& AlonsoSpilsbury, M., 2006. Effects of mid-summer duration on pre- and post-slaughter performance and pork quality in Mexico, Meat Sci. 73, 404-412.

Muchenje, V., Dzama, K., Chimonyo, M., Raats, J.G. \& Strydom, P.E., 2008. Meat quality of Nguni, Bonsmara and Aberdeen Angus steers raised on natural pasture in the Eastern Cape, South Africa, Meat Sci. 79, 20-28.

Muchenje, V., Dzama, K., Chimonyo, M., Strydom, P.E., Hugo, A. \& Raats, J.G., 2009. Some biochemical aspects pertaining to beef eating quality and consumer health: A review. Food Chem. 112, 279-289.

Rodríguez, A.B., Bodas, R., Landa, R., Copez-Campos, O., Mantecon, A.R. \& Giraldez, F.J. 2011. Animal performance, carcass traits and meat characteristics of Assaf and Merino x Assaf growing lambs. Livest. Sci. 138, 13-19.

SAS, 2003. Statistical Analysis System: Guide to Personal Computers, Version 6, Statistical Analysis System Institute Inc. Cary, N.C., USA.

Schönfeldt, H.C. \& Strydom, P.E., 2011. Effect of age and cut on cooking loss, juiciness and flavour of South African beef. Meat Sci. 87, 180-190. 